\title{
A Rapid, Reliable and Less-destructive On-chip Mass Measurement for 3D Composite Material Testing Microstructures
}

Gilgueng Hwang, Christophe David, Alisier Paris, Dominique Decanini, Ayako Mizushima, Yoshio Mita

\section{To cite this version:}

Gilgueng Hwang, Christophe David, Alisier Paris, Dominique Decanini, Ayako Mizushima, et al.. A Rapid, Reliable and Less-destructive On-chip Mass Measurement for 3D Composite Material Testing Microstructures. 2020 IEEE 33rd International Conference on Microelectronic Test Structures (ICMTS), May 2020, Edinburgh, U.K., United Kingdom. hal-03020646

\section{HAL Id: hal-03020646 \\ https://hal.archives-ouvertes.fr/hal-03020646}

Submitted on 24 Nov 2020

HAL is a multi-disciplinary open access archive for the deposit and dissemination of scientific research documents, whether they are published or not. The documents may come from teaching and research institutions in France or abroad, or from public or private research centers.
L'archive ouverte pluridisciplinaire HAL, est destinée au dépôt et à la diffusion de documents scientifiques de niveau recherche, publiés ou non, émanant des établissements d'enseignement et de recherche français ou étrangers, des laboratoires publics ou privés. 


\title{
A Rapid, Reliable and Less-destructive On-chip Mass Measurement for 3D Composite Material Testing Microstructures
}

\author{
Gilgueng Hwang ${ }^{1,2,3 *}$, Christophe David ${ }^{3}$, Alisier Paris ${ }^{3}$, Dominique Decanini ${ }^{3}$, Ayako Mizushima ${ }^{4}$, Yoshio Mita ${ }^{1,2}$ \\ ${ }^{1}$ LIMMS-CNRS, Institute of Industrial Science, University of Tokyo, Japan \\ ${ }^{2}$ Dept. of Electrical Engineering and Information Systems, The University of Tokyo, 113-8656 Japan \\ ${ }^{3} \mathrm{C} 2 \mathrm{~N}-\mathrm{CNRS}$, University Paris-Sud, University Paris-Saclay, Palaiseau, 91120 France \\ ${ }^{4}$ VLSI Design and Education Center, The University of Tokyo, 2-11-16, Yayoi, Bunkyo-ku, Tokyo 113-0032, Japan \\ *Email: hwang@if.t.u-tokyo.ac.jp, gilgueng.hwang@c2n.upsaclay.fr
}

\begin{abstract}
Mass measurements of complex three-dimensional microstructures are essential to the design and development of microsystems. However, the mass measurements of such microstructures require several manipulation steps which are not well controlled. We have demonstrated a rapid, reliable and lessdestructive on-chip mass measurement method by incorporating with AFM micromanipulation. It is based on AFM pick-measureplace micromanipulation using Van der Waals attraction and the mass measurement by resonant frequency shift. The measurement sensitivity revealed to be $25 \mathrm{~Hz} / \mathrm{pg}$ and it could be promising to characterize MEMS with complex geometries and composite materials.
\end{abstract}

\section{INTRODUCTION}

Recent advancement of micro/nanolithography technologies allows to fabricate 3D helical microstructures which are promising building blocks towards micro electromechanical system (MEMS) sensors and actuators. The self-scrolling technology has been studied by strain-engineering of epitaxially grown semiconductor bilayers $[1,2]$. Various other materials from metals to dielectrics could also be used by glancing angle deposition [3]. Direct laser writing by two-photon polymerization simplified 3D microfabrication [4] and allowed to fabricate $3 \mathrm{D}$ gold-helix photonic metamaterial by electrolytic growth [5] or deposition by sputtering [6]. However, such additional processes cause the volumetric variation in the final volume and mass from the initial design thus expected to optimize the process. This requires mass estimation of such composite $3 \mathrm{D}$ materials. The computational model estimation is limited to the simple models and could derive with errors from the real value. Therefore, experimental characterizations remain to be pertinent. The major challenge of measuring the mass of fabricated 3D composite microstructures is due to their fragile mechanics which can cause the loss of materials during the measurement.

In this work, we propose a rapid, reliable and less-destructive method to measure the mass of such $3 \mathrm{D}$ microstructures. The method is performed by an atomic force microscope (AFM) micromanipulation steps combining both the tapping mode and the contact mode. Using AFM as micromanipulator as well as mass sensor, mass measurements can be done on the fabrication substrate of the target samples. Compared to conventional

\begin{tabular}{|c|c|c|c|}
\hline & MEMS Sensor & $\begin{array}{c}\text { In-situ SEM } \\
\text { nanomanipulation }\end{array}$ & $\begin{array}{l}\text { Proposed } \\
\text { Method }\end{array}$ \\
\hline Environment & Air & Vacuum & Air \\
\hline Measurement & Hysteresis/Drift & Drift & Controlled \\
\hline $\begin{array}{c}\text { Sample } \\
\text { Contamination }\end{array}$ & $\begin{array}{c}\text { Mass variations } \\
\text { (addition or } \\
\text { loss) }\end{array}$ & $\begin{array}{l}\text { Mass variations } \\
\text { (glue or ebeam } \\
\text { deposition) }\end{array}$ & Minimum \\
\hline $\begin{array}{c}\text { Sample } \\
\text { placement }\end{array}$ & Not-controlled & Controlled & Controlled \\
\hline $\begin{array}{c}\text { Sample } \\
\text { attachment }\end{array}$ & Van der Waals & $\begin{array}{l}\text { Chemical glue or } \\
\text { ebeam deposition }\end{array}$ & Van der Waals \\
\hline $\begin{array}{c}\text { Reconfigure/ } \\
\text { Repeatable }\end{array}$ & No & No & Yes \\
\hline Process time & $\begin{array}{c}\text { Long } \\
\text { (sample } \\
\text { transport) }\end{array}$ & $\begin{array}{c}\text { Long } \\
\text { (require vacuum, } \\
\text { deposition) }\end{array}$ & $\begin{array}{c}\text { Short } \\
\text { (direct } \\
\text { measurement) }\end{array}$ \\
\hline
\end{tabular}

Table 1: Comparison of the proposed method with others

approaches such as MEMS mass sensor or in-situ scanning electron microscope (SEM) nanomanipulation, this on-chip measurement can avoid additional transportation process from fabrication substrate to MEMS mass sensor (Table 1). The paper describes first on the fabrication of 3D composite material microstructures fabricated on the supporting pillars. Then we describe the chemical-free micromanipulation strategy for the mass measurements with minimal addition or loss. Finally

\section{3D COMPOSITE MATERIAL MicROSTRUCTURES}

To demonstrate such characteristics, it is important to prepare samples for this process. We fabricated the triple bihelical test microstructures with polymer and metallic layers which are promising building blocks towards the wireless electromagnetic actuators or sensors [7] (Fig. 1). The helical structures were made by two-photon polymerization using 3D laser nanolithography system (Nanoscribe $\mathrm{GmbH}$ ). The helical test structures are suspended onto the conical micropillars which elevate $5 \mu \mathrm{m}$ above the substrate surface thus to avoid shadow effect during deposition of other layers. The metallic layers ( $\mathrm{Cr} / \mathrm{Ni}$ 10/200nm) were deposited by sputtering to maximize the deposition uniformity. The uniformly coated layers with minimum non-metalized area (the point contact with conical micropillars) and the conical supporting pillars from the 


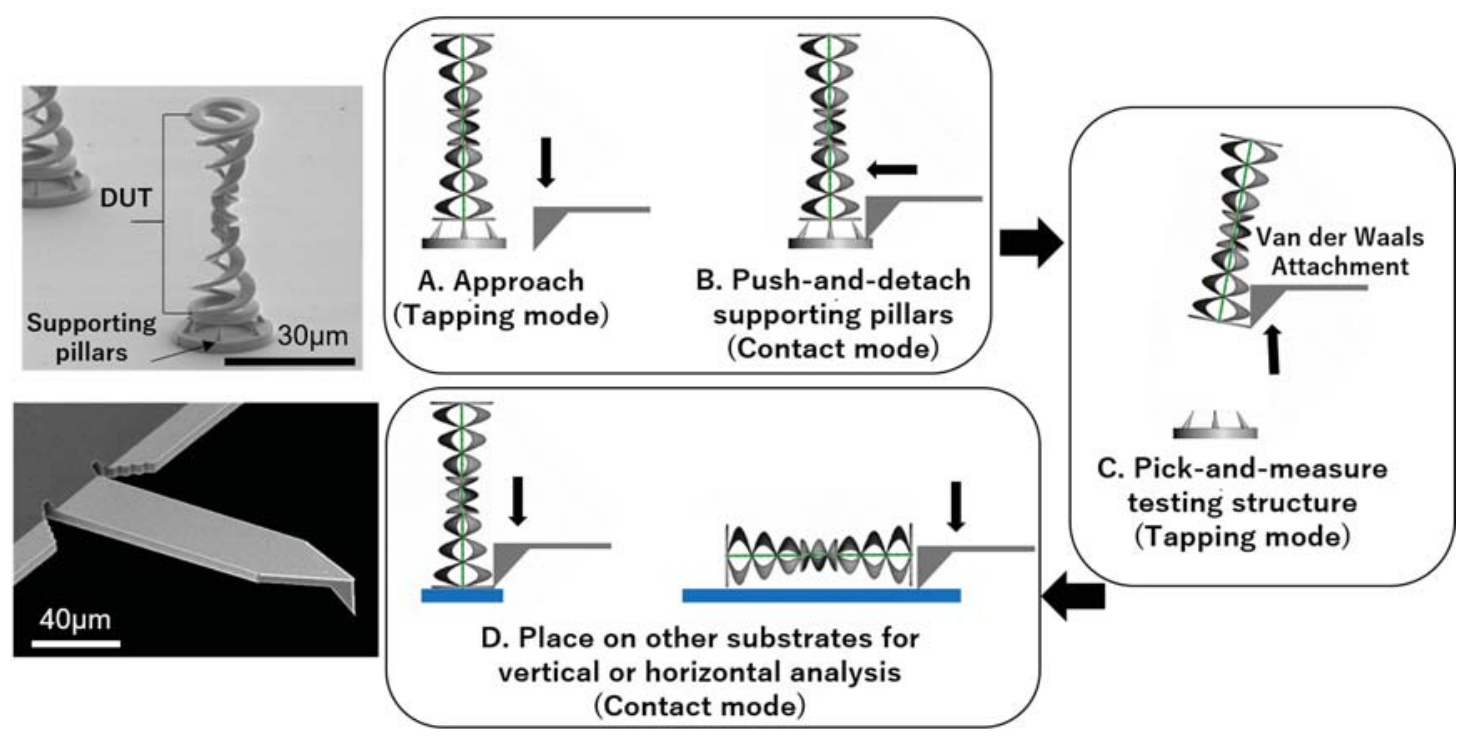

Figure 1: 3D helical test microstructure and AFM cantilever. Schematic concept of pick-measure-place testing structures.

substrate allow to detach easily the helical structure by AFM cantilever (Fig. 1) without losing the mass.

\section{Micromanipulation of Testing MicrostruCture}

Since the fabricated microstructures are fixed on the substrate, several micromanipulation steps are required to prepare for the mass measurements. This includes the detachement out of substrate and the attachment to AFM tip.

\section{A. Detachement of Microstructures from Substrate}

To demonstrate such characteristics, it is important to prepare samples for this process. We fabricated the triple bihelical test microstructures with polymer and metallic layers which are promising building blocks towards the wireless electromagnetic actuators or sensors [7] (Fig. 1). The helical structures were made by two-photon polymerization using 3D laser nanolithography system (Nanoscribe $\mathrm{GmbH}$ ). The helical test structures are suspended onto the conical micropillars which elevate $5 \mu \mathrm{m}$ above the substrate surface thus to avoid shadow effect during deposition of other layers. The metallic layers $(\mathrm{Cr} / \mathrm{Ni} 10 / 200 \mathrm{~nm})$ were deposited by sputtering to maximize the deposition uniformity. The uniformly coated layers with minimum non-metalized area (the point contact with conical micropillars) and the conical supporting pillars from the substrate allow to detach easily the helical structure by AFM cantilever (Fig. 1) without losing the mass.

The detachments of the microstructures out of the fabrication substrates are important but conventional micromanipulation approaches are not free from the addition or loss of mass mainly due to the requirement of brutal manipulation or chemical solutions. Therefore, here we propose a chemical-free and controlled detachment process. The specially designed 6 supporting pillars with minimum surface contact area with testing microstructures. The pillars are conical to keep mechanical stability to hold the testing microstructure during fabrication and transport processes. And it also helps to minimize the contact area which is the main source of potential mass addition or loss during the detachment process.

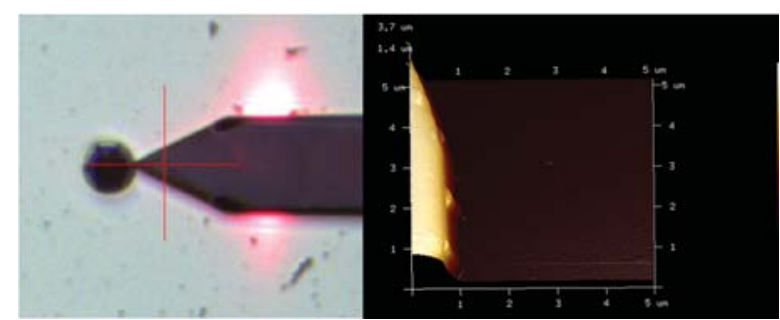

Figure 2: Scanning topography around the bottom supporting ring for a fine position.

In addition, we attempted to control better the micromanipulation process to detach the testing microstructure. AFM tip is engaged near to the supporting structure to avoid any potential damage. Then the tapping mode with scanning the interface area to the supporting structure. This is to be sure to precisely place the AFM probe tip on top of the bottom supporting ring. Without having this process step, the detachment can include the supporting structure which results in a wrong measurement. Figure 3 shows the scanned image and photograph of the AFM tip adjacent to the supporting ring. Based on the AFM topography, the AFM tip is moved on to the supporting ring. Then the supporting pillars are disconnected by moving further towards the center of the ring.

The disconnected microstructure is attracted electrostatically to the AFM tip and attached to it. Once it is attached, the AFM tip is moved vertically to $\mathrm{Z}$ axis to free the microstructure out of the substrate. We perform the mass measurement at this step. Once the measurement is done, we place the microstructure to the target substrate. Figure 3 shows the sequence of manipulation.

\section{B. Attachement of AFM Probe and Microstructure}

It is also crucial to avoid any possible addition or loss of mass during the mass measurement process. One of the major sources of the addition of mass could be caused from the addition of 

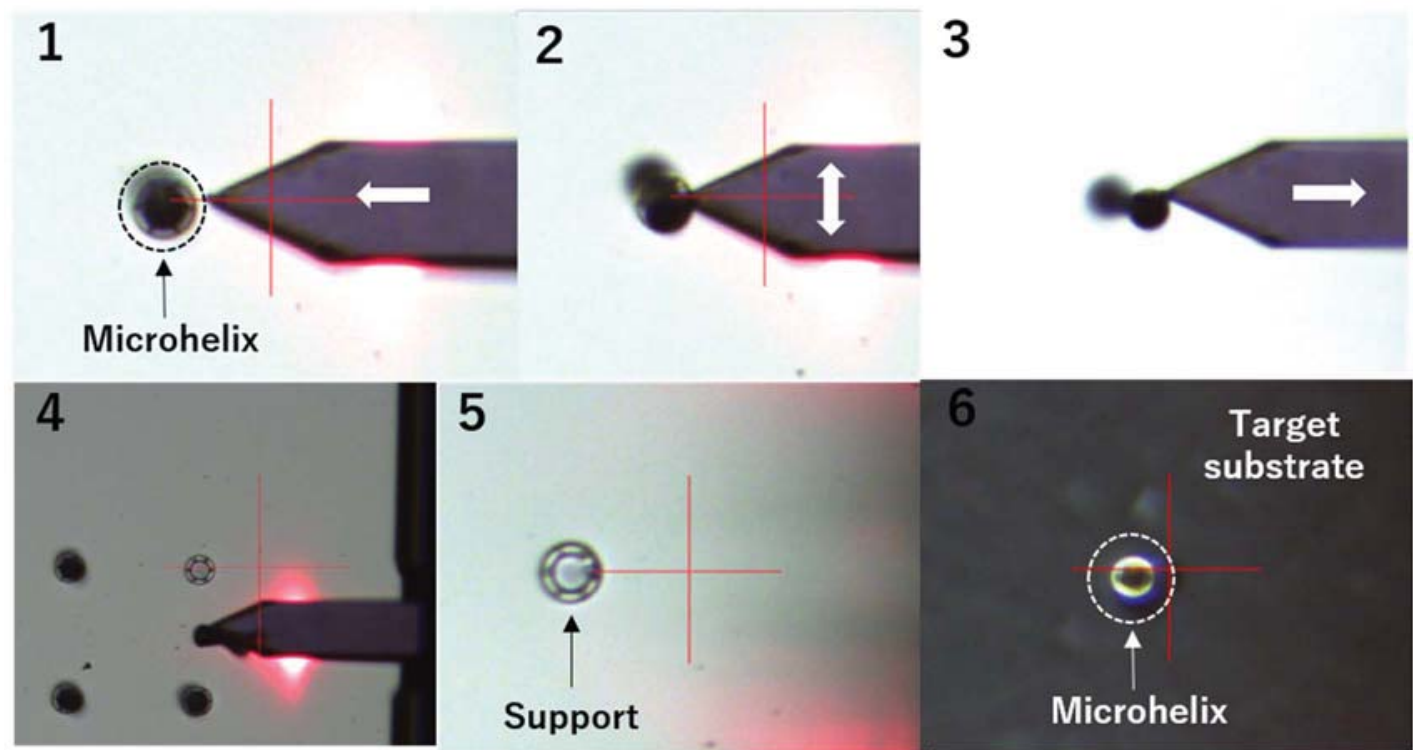

Figure 3: Pick-measure-place micromanipulation by AFM: 1. AFM tip is placed on top of the bottom support ring between two supporting pillars and move towards the center of microhelix, 2. AFM tip is moved laterally to disconnect the microhelix from supporting pillars, 3. Retraction of AFM tip out of the microhelix, 4. Moving up the picked-up microhelix with AFM tip, 5. Verification of the remained bottom supporting ring, 6. The microhelix is placed on to other substrates for further analyses.

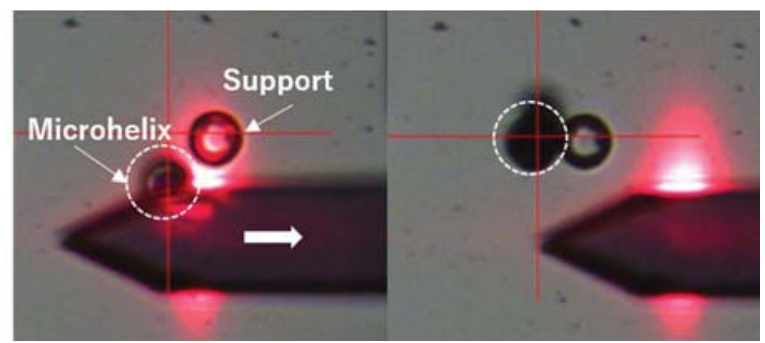

Figure 4: Placing back the 3D microhelix onto substrate.

chemical glue dispensed to fix the AFM tip and the testing microstructure. For this concern, we chose to use Van der Waals force for the attachment. This will allow the attachment to be reversible. In addition, electrostatic force induced from the charged AFM tip helps to hold the attachment firmly during the handling and the measurement.

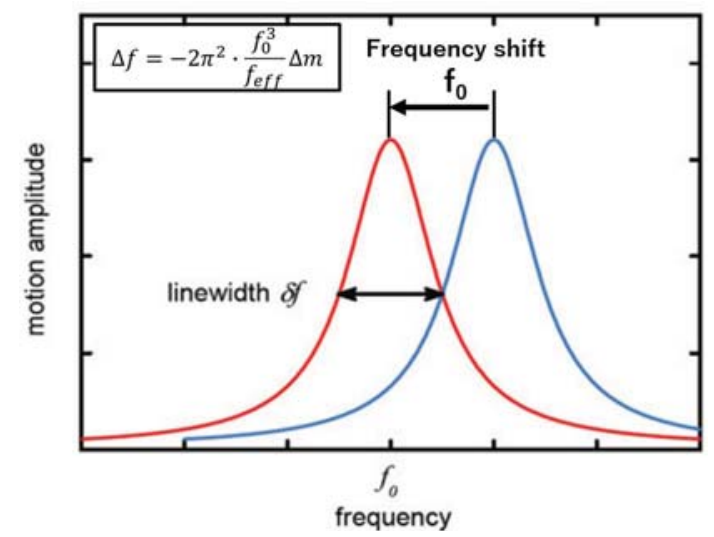

Figure 5: Mass sensing by resonant frequency shift
Once the measurement is completed, the tested microstructure can be released out of the AFM tip for the next measurements. This can be made by placing the microstructure onto the substrate thanks to the fact that the microstructure's contact surface area to the substrate is higher than the one to the AFM tip (Figure 4). Moreover, the engagement of the AFM tip with the substate will apply a minimal force sufficient to deflect the helical microstructures attached to the AFM tip thus allows to break the contact between the AFM tip and the microstructure. The remaining surface charge induced electrostatic force can also be reduced during the surface contact mode which makes easier the release process of the microstructures.

\section{Mass Measurements of Microstructures}

The micromanipulation allows to handle testing microstructures. In this section, mass measurements and further analyses of the testing microstructures are described.

Prior and posterior to the mass measurements, we will need to perform following micromanipulation. To briefly summarize, the calibrated AFM tip is approached near to the bottom supporting part of the target sample. Surface scanning by AFM tip gives topographical information at the interface between the support ring and substrate. This allows to optimize the precise positioning of the AFM tip for the further releasing process (Fig. 2 ). Then a sequence of pick-measure-place is performed by contact mode micromanipulation of AFM tip (Figs. 1 and 2). The AFM switches back to tapping mode after the target sample is picked up in air and another thermal calibration is performed to obtain resonant frequency of the AFM cantilever with added mass of target sample. The addition of a small mass $\Delta \mathrm{m}$ of compared to that of the cantilever causes the shift in the resonant 


\begin{tabular}{|c|c|c|c|}
\hline Sample & Mass $(\mathrm{pg})$ & Frequency $\Delta \mathrm{f}(\mathrm{Hz})$ & Sensitivity $(\mathrm{Hz} / \mathrm{pg})$ \\
\hline 1 & $1647 \pm 1$ & 40750 & $25 \pm 1$ \\
\hline 2 & $2142 \pm 1$ & 53618 & $25 \pm 1$ \\
\hline 3 & $1406 \pm 1$ & 35339 & $25 \pm 1$ \\
\hline 4 & $1827 \pm 1$ & 44492 & $24 \pm 1$ \\
\hline 5 & $1334 \pm 1$ & 32077 & $24 \pm 1$ \\
\hline 6 & $1579 \pm 1$ & 39176 & $25 \pm 1$ \\
\hline
\end{tabular}

Table 2: Measurements of mass and sensitivity.

frequency $\Delta \mathrm{f}$. With the constant stiffness of the cantilever, the resonant frequency variation is given by the first order approximation [8]:

$$
\Delta \mathrm{f}=-2 \pi^{2} \cdot \Delta \mathrm{m} \cdot \mathrm{f}^{3} / \mathrm{k}_{\mathrm{eff}}
$$

Once the measurement is made, the AFM tip with the $3 \mathrm{D}$ helix moves back to the substrate to place the measured samples back for other measurements (Fig. 4). This pick-measure-place can be repeatedly performed with same sample or different samples and resonant frequencies are measured at each time (Fig. 5). The 6 different types of samples with slight geometrical modifications were tested to reveal the mass of each and the measurement sensitivity (Table 2). The mass was ranging from $1334 \mathrm{pg}$ to $2142 \mathrm{pg}$ and the sensitivity was revealed to be 25 $\mathrm{Hz} / \mathrm{pg}$. Iterative measurements of identical testing microstructure with pick-and-place manipulations showed that the deviation of the measured mass is within the sensitivity.

Further analyses of the deposited layer thickness were also able to be made and it could be useful to identify the measured mass of inner resist layer and the deposited layers (Figure 6). AFM tip scanned on an area over the interface between the masked (not deposited) area and the deposited area. This reveals also the deposition quality by surface roughness. The deposited metal layer (aimed to deposit $\mathrm{Cr} / \mathrm{Ni} 10 / 200 \mathrm{~nm}$ ) thickness was measured around $216 \mathrm{~nm}$ (difference is less than 3\%). The roughness of the surface was measured around $2 \mathrm{~nm}$ (less than $1 \%$ of the total thickness). These are within the acceptable range of the quality of the additionally deposited layers.

Moreover, defects or morphological inspections can also be performed by rolling the 3D microhelix (Figure 7). For this purpose, we placed testing structure laterally on the substrate and used AFM tip to push to roll the structures. The analyses by SEM photographs reveal that the testing microstructures did not have any major deformations or damage during the whole manipulation and measurement processes. This makes the proposed process to be promising to the mass analyses of $3 \mathrm{D}$ complex and composite microstructures.

\section{CONCLUSIONS}

We proposed a mass measurement method by AFM for 3D complex shape composite microstructures. Specially designed supporting micropillars allowed the microstructures can be easily detached from fabrication substrate and attached to AFM tip for the mass measurement by resonant frequency shift. Thanks to the purely physical (chemical-free) micromanipulation, the measurement process can be made iteratively. The tested microstructures can be conserved for more measurements and also for further analyses such as electron microscopy. The proposed on-chip mass measurement method is shown to be rapid, reliable and less-destructive thus could be
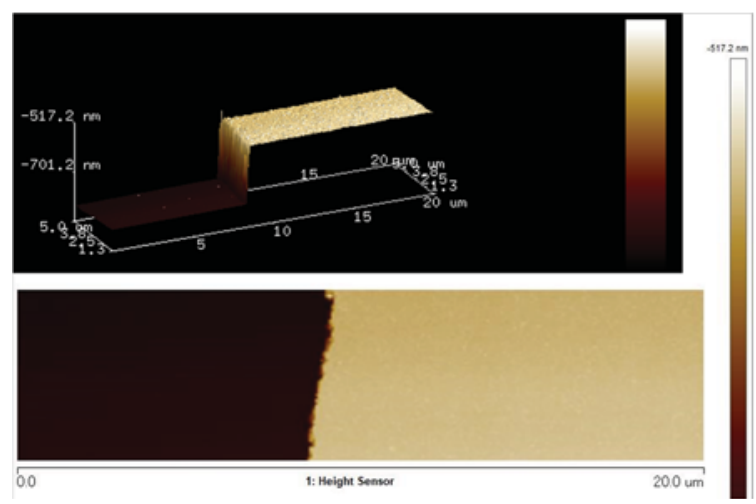

Figure 6: Deposited layer (bright) thickness analyses.

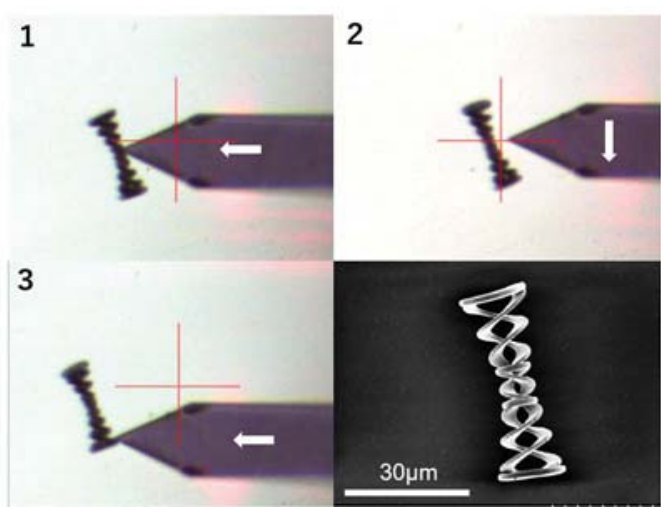

Figure 7: Morphological and defect analyses by rotating $3 D$ helical microstructure.

promising to test MEMS with 2D or 3D complex geometries and composite materials.

\section{ACKNOWLEDGMENT}

A part of this work is supported by Japan Society for the Promotion of Science (JSPS) through invitational fellowships for research in Japan. The test microstructure design, 3D nanolithography and AFM measurements were supported by the French RENATECH network through its $\mathrm{C} 2 \mathrm{~N}$ technological facility. Metallic layer deposition by sputtering was supported by MEXT/VDEC Nanotechnology Platform in The University of Tokyo.

\section{REFERENCES}

[1] D. J. Bell, L. Dong, B. J. Nelson, M. Golling, L. Zhang, D. Grutzmacher, Nano Letters, 6 (2006), pp. 725-729.

[2] G. Hwang, H. Hashimoto, D. J. Bell, L. Dong, B. J. Nelson, S. Schon, Nano Letters, 9 (2009), pp. 554-561.

[3] K. Robbie, M. J. Brett, J. Vac. Sci. Technol. A, 15(3) (1997), pp. 14601465 .

[4] S. Maruo, O. Nakamura, S. Kawata, Opt. Lett., 22 (1997), pp. 132

[5] J. K. Gansel, M. Latzel, A. Frolich, J. Kaschke, M. Thiel, M. Wegener, Appl. Phys. Lett., 100 (2012), pp. 101109.

[6] S. Tottori, L. Zhang, F. Qiu, K. K. Krawczyk, A. Franco-Obregon, B. Nelson, Adv. Mat., 24 (2012), pp. 811-816.

[7] A. Paris, D. Decanini, G. Hwang, Sens. Act.: A. Phys., 276 (2018), pp. 118-124.

[8] M. Mauro, R. Battaglia, G. Ferrini, R. Puglisi, D. Balduzzi, A. Galli, arXiv : $1410.1953(2014)$ 